\title{
CÁRCEL Y PANDEMIA \\ Profundización de una crisis permanente. El caso chileno
}

\author{
PRISON AND PANDEMIC \\ Deepening of a permanent crisis. The Chilean case
}

\section{Ángela Peralta Jordán*}

RESUMEN: En el presente artículo se abordan algunas de las políticas para la contención del Covid-19 adoptadas en los centros penitenciarios de Chile, partiendo de un diagnóstico de vulnerabilidad que afecta al grupo de personas reclusas, previo a la pandemia, pero que se profundiza con ella. Se propone la incorporación de la categoría de discriminación estructural en el sistema de ejecución penal, como una herramienta de análisis de la cuestión carcelaria.

ABSTRACT: This article addresses some of the policies for the containment of Covid-19 adopted in prisons in Chile, based on a vulnerability diagnosis that affects the group of people deprived of liberty, pre-pandemic, but which deepens with it. The incorporation of the category of structural discrimination in the penal execution system is proposed as an instrument for analyzing the prison crisis.

PALABRAS CLAVE: pandemia, personas privadas de libertad, discriminación estructural.

KEYWORDS: pandemic, people deprived of liberty, structural discrimination.

Fecha de recepción: 05/04/2021

Fecha de aceptación: 05/04/2021

doi: https://doi.org/10.20318/universitas.2021.6199

\footnotetext{
* Abogada de la Universidad de Valparaíso, Chile. Magíster en Estudios Avanzados en Derechos Humanos por la Universidad Carlos III de Madrid. Doctoranda en Derechos Humanos, Democracia y Justicia Internacional por la Universidad de Valencia.

E-mail: a.peraltajordan@gmail.com
} 


\section{1.- INTRODUCCIÓN}

El escenario de la pandemia nos invita a quienes estudiamos materias de derechos humanos a reflexionar, de forma crítica y siempre alerta, en torno a la manera en que han reaccionado los Estados para intentar controlar la expansión del virus Covid-19. Particularmente, resultan relevantes las preguntas relacionadas con las restricciones y limitaciones de derechos fundamentales, la manera en que se han tomado estas decisiones en las democracias actuales y la nueva forma de control social que aparece en este contexto extraordinario.

Estamos llamadas a constatar aquello que no se ve o que no se quiere mostrar, pero que está ocurriendo incluso en estos días. Esto implica reconocer la falsedad del carácter democrático del virus ${ }^{1}$ instalado en la mayoría de los discursos oficiales de los gobiernos, a fin de evidenciar que este no afecta por igual a todas las personas y/o grupos de la comunidad: mujeres, personas en situación migratoria irregular, trabajadoras/es precarios, informales o de la calle, ancianas/os, personas privadas de libertad, población sin acceso a un sistema de salud digno, entre otros, son desigualmente afectados por el virus, precisamente, por la desigualdad sistémica que afecta previamente a estos colectivos. No somos igualmente capaces de enfrentar esta pandemia.

En este contexto el grupo de personas reclusas ha sido duramente afectado, no solo por el confinamiento dentro del encierro, sino por la profundización de las restricciones de derechos fundamentales que escapan a la sentencia que ordena la privación de libertad; algo que parecía imposible -pues la crisis permanece instalada desde hace décadas en nuestra región- se evidenció con la llegada del Covid-19. En efecto, las (malas) condiciones materiales que sufren las y los miembros de este grupo desde que la cárcel existe y la invisibilización/naturalización de esta realidad por parte de los Estados, ya nos hacía presagiar las (insuficientes) políticas públicas que se adoptarían al interior de los establecimientos penitenciarios para la contención del virus.

\section{2.- PERSONAS PRIVADAS DE LIBERTAD: UN GRUPO EN SITUACIÓN DE VULNERABILIDAD. FASE PRE-PANDEMIA}

Los Estados justificaron la restricción y/o limitación de la libertad ambulatoria y el acceso a otros derechos fundamentales de la población en general, con el fin de preservar la salud pública; sin embargo, algunas de estas restricciones no son nuevas para las personas reclusas. La crisis no es excepcional ni surgió con la llegada

1 Iñaki Rivera Beiras, "El nuevo Gran Encierro de la Modernidad Tardía" en Iñaki Rivera Beiras (Coord.) Pandemia. Derechos Humanos, Sistema Penal y Control Social (en tiempos de coronavirus) (Tirant Humanidades, 2020), p. 31. 
de la pandemia, por el contrario, acompaña a las y los miembros de este grupo desde que ingresan a la cárcel. Lo que para los Estados son medidas extraordinarias, justificadas por la emergencia sanitaria, pero adoptadas en el marco de un sistema democrático, para la población penitenciaria son elementos estructurales de la prisión. Lo que llaman excepción en el medio libre es la regla al interior de la cárcel, en lo que a la restricción de derechos se refiere.

Con esto quiero decir que la desregulación y el mal funcionamiento del sistema penitenciario en general, amenaza y perturba constantemente la vida y la integridad física y psíquica de las y los internos, mediante acciones u omisión de agentes estatales, a pesar de encontrarse estos en una posición de garante. Desde esta perspectiva, la vulneración de los derechos fundamentales de las personas privadas de libertad se manifiesta, en gran medida, como violencia institucional ${ }^{2}$.

Veamos el ejemplo de Chile -desde donde escribo- aunque se trate de una realidad generalizada o compartida en gran parte de Latinoamérica $^{3}$. Respecto a las cifras de ocupación carcelaria y condiciones de habitabilidad e infraestructura ${ }^{4}$, el $50 \%$ de los penales se encuentran en niveles de sobreocupación, hacinamiento alto o crítico, lo que implica en la práctica una serie de consecuencias atentatorias a la integridad personal como la falta de camas, calefacción y servicios higiénicos al interior de las celdas, acceso limitado al agua, presencia de instalaciones eléctricas peligrosas, falta de condiciones adecuadas de salubridad y sanidad, etc. ${ }^{5}$

\footnotetext{
2 Para un análisis completo de la violencia institucional carcelaria en Latinoamérica véase Eurosocial, Diagnóstico de la violencia institucional en las prisiones de América Latina: sistemas y buenas prácticas para su respuesta y atención (2018) https://eurosocial.eu/biblioteca/doc/diagnostico-de-la-violencia-institucional-en-lasprisiones-de-america-latina/ fecha de acceso 5 de abril de 2021.

3 Para un panorama de la región véase Elías Carranza, "Situación penitenciaria en América Latina y el Caribe ¿Qué hacer?" en Anuario de Derechos Humanos (2012).

4 Al respecto la Comisión Interamericana de Derechos Humanos señaló: "El hacinamiento de personas privadas de libertad genera fricciones constantes entre los reclusos e incrementa los niveles de violencia en las cárceles; dificulta que éstos dispongan de un mínimo de privacidad; reduce los espacios de acceso a las duchas, baños, el patio etc.; facilita la propagación de enfermedades; crea un ambiente en el que las condiciones de salubridad, sanitarias y de higiene son deplorables; constituye un factor de riesgo de incendios y otras situaciones de emergencia; $e$ impide el acceso a las -generalmente escasas- oportunidades de estudio y trabajo, constituyendo una verdadera barrera para el cumplimiento de los fines de la pena privativa de la libertad". Comisión Interamericana de Derechos Humanos, Informe sobre los derechos humanos de las personas privadas de libertad en las Américas (núm. 455, 2011) https://www.oas.org/es/cidh/ppl/docs/pdf/ppl2011esp.pdf fecha de acceso 5 de abril de 2021.

5 Instituto Nacional de Derechos Humanos, Estudio de las condiciones carcelarias en Chile. Diagnóstico del cumplimiento de los estándares internacionales de derechos humanos sobre el derecho a la integridad personal 2016-2017 (2018) https://bibliotecadigital.indh.cl/handle/123456789/1180 fecha de acceso 5 de abril de 2021. Antes, el Subcomité para la Prevención de la Tortura y Otros Tratos o
} 
En cuanto a la falta de acceso a la asistencia médica, la principal causa de muerte entre los años 2000 y 2018 fue algún tipo de enfermedad. ${ }^{6}$ Lo anterior se debe, principalmente, a la "baja calidad de atención debido a los escasos medios disponibles en las cárceles [infraestructura e insumos médicos], a la falta de personal calificado [un médico por cada 909 privados de libertad aproximadamente] y a las dificultades que se presentan para derivar a las persona reclusas a centros externos donde puedan ser atendidas". ${ }^{7}$

Luego, se vulnera también la integridad física de las personas privadas de libertad cuando se les somete a sanciones reglamentarias (como el aislamiento en celdas solitarias) ${ }^{8}$ y extrarreglamentarias (como el conocido "pago al contado" en que el gendarme golpea u obliga a realizar ejercicio físico a un interno/a a cambio de no registrar alguna falta disciplinaria). ${ }^{9}$

No obstante, este diagnóstico no se limita a una cuestión meramente fáctica. El respaldo normativo e institucional a dicha situación tolera, avala e impulsa la condición de vulnerabilidad de las personas privadas de libertad, en tanto sostiene una estructura

Penas Crueles, Inhumanos o Degradantes, observó la "falta de espacio para dormir, basura generalizada, roedores, plagas de chinches, carencia absoluta de higiene", etc. Subcomité para la Prevención de la Tortura y Otros Tratos o Penas Crueles, Visita a Chile: recomendaciones y observaciones dirigidas al Estado parte (4-13 de abril de 2016) para. 72 http://docstore.ohchr.org/SelfServices/FilesHandler.ashx?enc=6QkG1d\%2FPPRiCAq hKb7yhsgPEpOPkPvYO\%2F7DAnrKRrASeCSZxJynm8Gh12SesHiDLXFrhVtTB66PZWK OGKjnv\%2FYyyA5iTQDO\%2Bg6KHeTa7EDZcXH2ee4dfwkXhewCfeGhz fecha de acceso 5 de abril de 2021. En la misma línea, la Fiscalía Judicial de la Corte Suprema recalcó, además, como agravante de dicha situación de hacinamiento de los recintos penitenciarios la permanencia de las y los internos en sus celdas (generalmente carentes de servicios higiénicos, luz y ventilación adecuada) por espacios temporales aproximados de 15 horas diarias, lo que significa, en algunos casos, largas horas sin recibir alimento. Fiscalía Judicial Corte Suprema, Informe Principales problemas detectados en las visitas de cárceles realizadas el año 2017 por los fiscales judiciales (2018) http://decs.pjud.cl/informe-establecimientospenitenciarios-en-chile/ fecha de acceso 5 de abril de 2021.

6 Centro de Derechos Humanos Facultad de Derecho Universidad Diego Portales, "Las personas privadas de libertad y el acceso a prestaciones de salud en las cárceles chilenas", en Informe Anual sobre Derechos Humanos en Chile (2019) p. 463, https://derechoshumanos.udp.cl/informe-anual/informe-anual-sobrederechos-humanos-en-chile-2019-2/ fecha de acceso 5 de abril de 2021.

7 ibíd., pp. 475 y ss.

8 Además, constató la Fiscalía Judicial Corte Suprema la permanencia de personas privadas de libertad en celdas solitarias por periodos superiores a 60 días (también en deficientes condiciones higiénicas) por razones de seguridad del propio interno $o$ interna o por circunstancias provisorias mientras estos se encontraban en tránsito hacia otro recinto penitenciario definitivo. Fiscalía Judicial Corte Suprema, Informe Principales problemas detectados en las visitas de cárceles realizadas el año 2017 por los fiscales judiciales, cit.

9 Instituto Nacional de Derechos Humanos, Estudio de las condiciones carcelarias en Chile. Diagnóstico del cumplimiento de los estándares internacionales de derechos humanos sobre el derecho a la integridad personal 2016-2017, cit. 
penitenciaria incapaz de proteger los derechos humanos de quienes se encuentran en una posición de indefensión frente al Estado ${ }^{10}$. De ahí que Ferrajoli se refiera a la cárcel como una contradicción institucional:

Es un lugar confiado al control total del Estado, pero en cuyo interior no rigen controles ni reglas sino sobre todo la ley del más fuerte: la ley de la fuerza pública de los agentes penitenciarios y la fuerza privada de los presos más prepotentes y organizados. Es una institución pública dirigida a la custodia de los ciudadanos pero que no logra garantizar los derechos fundamentales más elementales, empezando por el derecho a la vida. ${ }^{11}$

Es así como la violencia institucional que opera al interior de la cárcel se vincula a la vulnerabilidad sistémica ${ }^{12}$, esta es, la que deriva de "determinada organización jurídica, política y social que hace vulnerables a ciertos grupos sociales por encontrarse en determinadas circunstancias o por poseer determinados caracteres identitarios, provocándoles un daño, lesión o discriminación"13. Un tipo de vulnerabilidad que, desde un enfoque intergrupal, implica la ubicación de determinadas personas en una posición inferior en la escala social y de poder.

Sobre los rasgos identitarios del colectivo que influyen en su situación de vulnerabilidad, Young sostiene que "un grupo social no se define principalmente por una serie de atributos compartidos, sino por un sentimiento de identidad"14, que puede venir determinado por la forma en que otras personas lo identifican, siguiendo en esta tarea una serie de normas sociales negativas y estereotipos. ${ }^{15}$ Dicho de otro modo, es posible que el grupo social exista en tanto otro lo excluye y categoriza, gestándose una identidad "sobre la base de la opresión compartida". ${ }^{16}$ Se coloca al grupo en una posición de subordinación durante un tiempo considerable (en lo que Fiss llama

10 A modo de ejemplo, el ordenamiento jurídico chileno no consagra constitucionalmente el principio de reintegración social -especialmente relevante en materia penitenciaria-, no contempla una ley de ejecución de penas que regule íntegramente la actividad al interior de la cárcel ni tampoco la figura del juez de vigilancia penitenciaria.

11 Luigi Ferrajoli, "Jurisdicción y ejecución penal. La Cárcel: una contradicción institucional" en Iñaki Rivera Beiras (Trad.) Revista Crítica Penal y Poder (núm. 11, 2016) pp. 1-10, p. 7.

12 María Ángeles Barrere Unzueta, "Marta A. Fineman y la igualdad jurídica: ¿Vulnerabilidad vs. Subordiscriminación?", en Cuadernos Electrónicos de Filosofía del Derecho (núm. 34, 2016) pp. 17-34, p. 32.

13 Silvina Ribotta, "Reglas de Brasilia sobre acceso a la justicia de las personas en condición de vulnerabilidad. Vulnerabilidad, pobreza y acceso a la justicia", en Centro de Estudios Iberoamérica, Revista Electrónica Iberoamericana (vol. 6, núm. 2, 2012) pp. 77-114, p. 84.

14 Iris Marion Young, La justicia y la política de la diferencia (Cátedra, Madrid, 2000), p. 79.

15 ibíd., p. 82.

16 ibíd., p. 83. 
"subordinación prolongada" o "sometimiento perpetuo"), determinando con ello el estatus de cada uno de sus miembros. ${ }^{17}$

En este sentido, la situación específica del grupo de personas reclusas se puede analizar a partir de la convergencia de dos factores de exclusión y categorización que determinan su identidad, a saber: la pobreza y la privación de libertad propiamente tal.

Esta afirmación encuentra su base en las teorías sobre la selectividad del poder punitivo y el encarcelamiento de la pobreza, conforme a las cuales la mayor parte de la población penitenciaria constituye un conjunto de personas relativamente homogéneo en términos de educación y empleo, y cuyos indicadores sociales se encuentran por debajo de la media del país, siendo dicha homogeneidad expresión de condiciones de exclusión anteriores a la cárcel y que se relacionan con la pobreza. ${ }^{18}$

De este modo, se asocia pobreza con delincuencia y se dirige la persecución penal hacia los sectores más desfavorecidos de la población. El poder punitivo se muestra entonces como "un hecho de la realidad del poder, un factum o hecho político"19 que distingue entre el "nosotros" (ciudadanos buenos, normales y respetuosos de la ley) y el "enemigo de la sociedad"20 (delincuente, desviado, anormal), negando a este último su condición de persona para considerarlo un ente peligroso o dañino. ${ }^{21}$ Como sostiene Cancio Meliá, el Derecho penal (en su función simbólica) "persigue la construcción de una determinada imagen de la identidad social

17 Owen M. Fiss, "Grupos y cláusula de igual protección", en Roberto Gargarella (Comp.), Derecho y grupos desaventajados (Gedisa, Barcelona, 1999), pp.137-167, pp. 139 y ss.

18 En Chile "las prácticas delictuales y el aumento evidente de ellas, están asociadas a trayectorias de vidas marcadas por el maltrato físico y psicológico, la deserción temprana de la escuela, la condición de abandono, la precarización del empleo y la ausencia de una red de apoyo estatal contundente capaz de reponer las carencias que no estaban en condiciones de ser proporcionadas por el entorno afectivo inmediato de un individuo". Fernando Codoceo y Fernanda Ampuero, "Apuntes iniciales sobre la instrumentalización política del "Sujeto peligroso"", en Fernando Codoceo, Fernanda Ampuero y Cecilia Pérez (Comps.), Criminalización de la pobreza. La construcción política del sujeto peligroso (Andros, Osorno, 2016) pp. 24-31, p. 24.

19 Eugenio Raúl Zaffaroni, Estructura básica del Derecho penal, Material de la cátedra de Teoría del Delito del Prof. Matías Bailone en la Maestría en Derecho Penal de la Universidad Andina Simón Bolívar (Ecuador) p. 6, http://www.matiasbailone.com/dip/Zaffaroni\%20-

\%20Estructura\%20Basica\%20de\%20Derecho\%20Penal.pdf fecha de acceso 5 de abril de 2021.

20 Jakobs caracteriza el Derecho penal del enemigo sobre tres elementos: el adelantamiento de la punibilidad, desproporción en las penas y relativización o supresión de determinadas garantías procesales. Günther Jakobs y Manuel Cancio Meliá, Derecho penal del enemigo (Thomson Civitas, Madrid, 2003), pp. 79-81.

21 Eugenio Raúl Zaffaroni, El enemigo en el Derecho penal (Ediar, Buenos Aires, 2006) p. 18. 
mediante la definición de los autores como "otros", como no partícipes de esa identidad" 22 .

Entonces, se traza una línea divisoria que separa al grupo dominante de los subordinados, imponiendo un "derecho penal máximo, máximamente duro contra la delincuencia de los pobres, delincuencia de subsistencia; [y un] derecho penal mínimo, máximamente leve e indulgente contra los crímenes del poder, la corrupción y la bancarrota". 23

Luego, se profundizan estos estereotipos con la sistemática vulneración de derechos fundamentales propia de la cárcel. Pues si bien la condena implica la restricción legítima de determinados derechos y libertades, como la libertad ambulatoria, no lo es la extensión de esta a otros derechos humanos como el acceso a la salud, a la educación, el derecho a no ser torturado/a, entre otros. Dicho de otro modo, la conformación del grupo no viene dada por la mera condición de persona privada de libertad, sino por la vulnerabilidad en la que esta se encuentra cuando se le restringen otros derechos al interior de la cárcel.

Normativamente, imperan en materia penal los principios de humanidad, proporcionalidad y prohibición de doble punición ${ }^{24} y$, sin embargo, lo que prevalece al interior de la cárcel es todo lo contrario: condiciones carcelarias próximas (sino constitutivas) a la tortura; alteración cualitativa de la pena impuesta en tanto se suman vulneraciones de derechos ajenas a la condena al punto de modificarla -esto sin considerar a las y los presos sin condena, en cuyo caso no existe siquiera un elemento de medición de proporcionalidad-; $y$, en definitiva, castigo dentro del castigo (en el caso de las personas condenadas) o pena anticipada (en el caso de las personas en prisión preventiva).

Finalmente, la criminalización de la pobreza, la profundización de estereotipos y la vulneración sistemática de derechos fundamentales no restringidos judicialmente en prisión, son elementos que han caracterizado al sistema carcelario desde sus inicios y que, a pesar de lo dispuesto en informes de organismos

22 Manuel Cancio Meliá, "De nuevo: ¿"Derecho penal" del enemigo", en Derecho penal del enemigo. El discurso penal de la exclusión, (vol. 1, Edisofer (España) Euro Editores (Buenos Aires) B de F (Uruguay), 2006) pp. 341-382, p. 355 . El autor redefine la idea de Derecho penal del enemigo como una fase evolutiva que resulta de la intersección de dos líneas de desarrollo: el Derecho penal simbólico (como mecanismo de creación de identidad social que excluye a determinadas personas del círculo de ciudadanos) y el punitivismo (incremento de penas como instrumento de control de la criminalidad).

23 Luigi Ferrajoli, "Criminología, Crímenes Globales y Derecho Penal. El debate epistemológico en la criminología contemporánea", en OSPDH (Trad.), Delitos de los Estados de los Mercados y daño social (Anthropos, Barcelona, 2014) pp. 81-96, pp. 94-95.

24 Santiago Mir Puig, Bases constitucionales del Derecho penal (Iustel, Madrid, 2011). 
fiscalizadores y en tratados internacionales sobre la materia, se han mantenido en el tiempo. De ahí que se hable aquí de "crisis permanente", pues esta nunca ha tenido un carácter excepcional: la cárcel ha funcionado siempre como un espacio de segregación de los excluidos. ${ }^{25}$

\section{3.- PROFUNDIZACIÓN DE LA CRISIS CARCELARIA DURANTE LA PANDEMIA}

La referida situación de vulnerabilidad que afecta al grupo de personas reclusas se profundizó con la llegada de la pandemia. Las medidas adoptadas por los gobiernos que restringieron gran parte de los derechos de las personas privadas de libertad de forma justificada, pues buscaban proteger el bien colectivo de la salud pública, implicaron también vulneraciones no justificadas, en muchos casos ilegales, precisamente por la incapacidad del sistema penitenciario para prevenir y contener la expansión de un virus de este tipo. A continuación se expondrán algunos ejemplos.

\section{1.- Derecho a recibir visitas}

La recomendación de suspender todo contacto entre las personas reclusas y las que viven en el medio exterior se sujetó al cumplimiento de determinados requisitos, tales como: la implementación gratuita y frecuente de métodos alternativos de comunicación con el exterior (como teléfonos u otros medios electrónicos idóneos) y de espacios apropiados que asegurasen la privacidad de las comunicaciones; y la posibilidad de recibir en todo momento encomiendas desde el exterior debidamente sanitizadas. ${ }^{26}$

En el caso de Chile, algunas de estas medidas se implementaron de forma inoportuna, es decir, con posterioridad a la adopción de la política de suspensión total de visitas, por lo que, en gran parte de los penales, más que restringirse este derecho se vulneró en su esencia. Con todo, y atendida la arquitectura que rige el sistema penitenciario, no se pudo garantizar la privacidad de las comunicaciones ni la entrega de encomiendas desde el exterior por la totalidad del tiempo en que estuvo suspendido el régimen de visitas. De hecho, resultó especialmente preocupante que, mientras comenzaba el desconfinamiento en el medio exterior (con apertura de

25 Sobre las causas que originan el fenómeno del encarcelamiento masivo, su componente de clase y las consecuencias dañinas que este genera en la sociedad, en la persona reclusa y su entorno más cercano, véase Iñaki Rivera Beiras, Descarcelación. Principios para una política pública de reducción de la cárcel (desde un garantismo radical) (2017) pp. 47 y ss.

26 Alto Comisionado de la ONU para los Derechos Humanos, Recomendación Subcomité Contra la Tortura (2020) https://acnudh.org/hay-que-tomar-medidasurgentes-para-evitar-que-el-covid-19-cause-estragos-en-las-prisiones/ fecha de acceso 5 de abril de 2021. 
centros comerciales, restaurantes, etc.) todavía no existía un protocolo que regulara la reanudación del derecho en comento ${ }^{27}$.

\section{2.- Protección de funcionarios penitenciarios}

En los hechos, quienes cumplen la función de resguardar la salud de las personas privadas de libertad en igualdad de condiciones respecto de quienes viven en el medio libre, son las y los funcionarios penitenciarios. Debido al contacto directo y permanente que estos mantienen con la población penitenciaria pero también con el exterior, resulta indispensable la adopción de una serie de medidas que tiendan a su protección como estrategia para impedir la expansión del virus al interior de la cárcel.

Entre ellas, se consideró en Chile la modificación del sistema de trabajo de los funcionarios de Gendarmería de Chile a uno flexible, a distancia y por turnos, lo que resultó de difícil aplicación debido al escaso personal que opera en la institución. En la práctica ocurrió que muchos funcionarios/as se contagiaron, el personal presente en los centros disminuyó considerablemente y con ello la falta de asistencia a las personas reclusas.

Esta situación de caos, el abandono del Estado en materia de prevención y control del virus y el alto nivel de desinformación de los familiares y personas más cercanas a las y los internos, provocó motines, huelgas de hambre y protestas al interior de los penales.

\section{3.- Aislamiento de personas reclusas}

El distanciamiento social, principal medida recomendada para el control de Covid-19, parece imposible al interior de la cárcel, debido a los niveles de hacinamiento y sobrepoblación antes referidos. Nuevamente, la arquitectura penitenciaria impidió e impide todavía la habilitación de espacios para el aislamiento adecuado de personas reclusas contagiadas o sospechosas de contagio. Esto provocó, en la práctica, la ubicación de estas en celdas solitarias o de castigo, conocidas por conservarse en pésimas condiciones de ventilación e higiene, transformando el aislamiento sanitario en uno de carácter disciplinario. 28

\section{4.- Derecho a la salud}

A la falta de condiciones materiales de habitabilidad e higiene antes descritas, se suma en la fase pre-pandémica la permanente restricción del derecho a recibir asistencia médica. A modo de

\footnotetext{
27 Recién el 14 de diciembre de 2020 se aplicó el Protocolo para el retorno gradual de visitas a establecimientos penitenciarios.

28 Corte Suprema de Chile, Situación recintos penitenciarios en pandemia COVID19 (2020).
} 
ejemplo, en Chile solo existe un Hospital Penitenciario radicado en la ciudad de Santiago; en los demás recintos operan unidades de asistencia médica primaria, pudiendo trasladar a la persona reclusa a un centro asistencial del medio exterior en determinados casos (generalmente los extremadamente graves), lo que suele producirse de forma tardía. ${ }^{29} \mathrm{Si}$ a esto se suma una pandemia, el escenario es desolador.

Veamos uno de los casos más preocupantes de Chile: la cárcel de Puente Alto. En abril de 2020 (esto es, a más de un mes de confirmarse el primer caso de Covid-19 en el país) la tasa de ocupación era de 226\%; el personal médico consistía en un doctor, un enfermero, tres técnicos paramédicos y un dentista; el centro contaba con solo un termómetro digital para toda la población penal y los familiares de los internos proporcionaban gran parte de los artículos de higiene y desinfección; la basura no era retirada con la debida frecuencia por lo que se acumulaba en los pasillos donde habitan los reclusos; los insumos de aseo, desinfección y protección, como guantes, alcohol, overoles desechables, mascarillas, antiparras, etc., eran insuficientes y los lugares de aislamiento no estaban condicionados adecuadamente. ${ }^{30}$

\section{5.- Excarcelación}

Como resulta lógico, diversos organismos recomendaron para la prevención y el control del Covid-19 al interior de las cárceles la adopción de medidas alternativas a la privación de libertad. ${ }^{31}$ Y si bien la tendencia de los Estados sigue siendo la utilización del Derecho penal como primera y a veces única herramienta para ejercer el control sobre la población, lo cierto es que se trata de una iniciativa que impacta directamente en la sobreocupación carcelaria y con ello en el control de la propagación del virus al interior de los penales.

En Chile, la Fiscal Judicial de la Corte Suprema informó que aproximadamente un tercio de las personas privadas de libertad egresaron de la cárcel desde el 18 de marzo al 31 de mayo de 2020, ya sea por aplicación de la Ley $\mathrm{N}^{\circ} 21.228$ sobre indulto que autorizó la conmutación de la pena privativa de la libertad por la de arresto domiciliario total a quienes cumplieran con determinados requisitos,

29 Centro de Derechos Humanos Facultad de Derecho Universidad Diego Portales, "Las personas privadas de libertad y el acceso a prestaciones de salud en las cárceles chilenas", cit. p. 463.

30 Colegio Médico de Chile, Informe visita al centro de detención preventiva de Puente Alto en el contexto de pandemia coronavirus COVID-19 en el marco de los derechos humanos de las personas privadas de libertad (2020).

31 Alto Comisionado de la ONU para los Derechos Humanos, Recomendación Subcomité Contra la Tortura (2020), cit. 
por el otorgamiento de la libertad condicional o por el cambio de medida cautelar de prisión preventiva. ${ }^{32}$

Una medida que podría considerarse adecuada en el contexto de emergencia sanitaria -pues descongestionó efectivamente el sistema penitenciario- pero no del todo suficiente si se mira el panorama completo. En efecto, con la aplicación de esta medida no se aseguró el acceso a la salud de las y los reclusos contagiados o bajo sospecha de contagio ni se proporcionaron más recursos para apalear la restricción del derecho a recibir visitas. Para garantizar estos y otros derechos se requieren cambios estructurales que vayan más allá de puntuales políticas de excarcelación.

\section{4.- UNA BREVE MIRADA DESDE LA CATEGORÍA DE DISCRIMINACIÓN ESTRUCTURAL}

El nulo acceso a condiciones de igualdad material y la falta de garantías que permitan el ejercicio efectivo de derechos de las personas privadas de libertad, formalmente reconocidos en cuerpos normativos (como el derecho a la vida, la salud, a no ser torturado/a, etc.), es una situación hoy día incuestionable pero pocas veces abordada desde la perspectiva del principio de igualdad y no discriminación; en particular, desde una categoría que permite ahondar en las causas de dicha desigualdad, como es la discriminación estructural.

A partir de las críticas a la visión individualista del principio de igualdad y falsamente universalista del individuo, aplicada en las categorías tradicionales de discriminación directa e indirecta ${ }^{33}$, y con la finalidad de vincular la noción de derecho antidiscriminatorio a la realidad que intenta superar -en este caso, la desigualdad sistémica-, la categoría de discriminación estructural permite realizar un análisis más completo de la discriminación pues contextualiza la situación del individuo en una estructura que oprime y domina a ciertos grupos y privilegia a otros, es decir, con un enfoque intergrupal. En este sentido, invita a romper la parcialidad del Derecho, captar las diferencias de estatus/poder y favorecer el desmantelamiento de la desigualdad estructural. ${ }^{34}$

Con tales objetivos, esta categoría se presenta, por una parte, como un criterio de interpretación normativa complementario al de

32 Fiscal Judicial de la Corte Suprema de Justicia, en La Segunda (2020) http://cache-elastic.emol.com/2020/06/05/B/5H3Q77BL/all fecha de acceso 5 de abril de 2021.

33 Individualista en tanto implica la imputación de una conducta concreta a partir de la aplicación de un test de comparación intersubjetivo, y falsamente universalista del individuo, pues solo algunos serán titulares de derechos, específicamente, los que se correspondan con la norma (asociada a lo dominante).

34 Neus Torbisco Casals, "La institucionalización de la diferencia: algunas notas sobre desigualdad estructural y democracia", en Los límites de la democracia (Editores del Puerto, Buenos Aires, 2005) pp. 35-56, p. 19. 
discriminación indirecta, que adiciona argumentos para la identificación de la desventaja y patrones discriminatorios, lo que implica, a su vez, la valoración de las desigualdades materiales ${ }^{35}$; y por otra, permea el ámbito de las acciones positivas que buscan equilibrar la situación de desventaja social de los grupos subordinados. 36

Analizando la situación de las personas privadas de libertad es posible sostener que existe discriminación en tanto se desvaloriza a sus miembros por los rasgos del colectivo al cual pertenecen. Tal como se señaló antes, el encarcelamiento de la pobreza, el estereotipo del delincuente-enemigo y las restricciones ilegales de derechos fundamentales en prisión son elementos que definen a este grupo y que obedecen a un sistema de opresión que permite política, social y jurídicamente la subordinación del mismo; de ahí su carácter estructural. Dicho de otro modo, hay un tratamiento diferenciado respecto de quienes viven en el medio libre, sin justificación razonable, pues se basa en un criterio no permitido como es la condición socio-económica del individuo.

Pues bien, en la labor de trasladar las figuras antidiscriminatorias al Derecho penitenciario, la teoría garantista de los derechos aparece como una buena estrategia para mejorar las condiciones de igualdad material de las personas privadas de libertad. En efecto, en tanto se comprenda el contexto de desventaja de este colectivo se podrán dirigir los esfuerzos a la protección de este, lo que implica, necesariamente, establecer un sistema de garantías que torne eficaces los derechos de sus miembros.

En el ámbito de la ejecución penal, el garantismo se traduce, precisamente, en la defensa del más débil, es decir, de la persona reclusa, lo que significa que la función que debe cumplir la pena, en esta sede, es la de minimizar la reacción violenta al delito dada por las penas inhumanas y vulneradoras de derechos fundamentales en condiciones de igualdad respecto de quienes se encuentran en el medio libre. Para esto se establecen una serie de principios (legalidad, proporcionalidad, humanidad de las penas y reintegración social) que constituyen el sustrato teórico de las garantías que se proponen.

Como resulta lógico, la primera iniciativa a considerar en el marco de estas garantías, es la superación de la propia institución segregadora y reproductora de desigualdades, mediante un cambio en el paradigma de persecución penal hacia uno que favorezca la

35 María José Añón Roig, "Principio antidiscriminatorio y determinación de la desventaja", en Isonomía (núm. 39, 2013) pp. 127-157, p. 147 y ss.

36 Roberto Saba, Más allá de la igualdad formal ante la ley ¿Qué les debe el Estado a los grupos desaventajados? (Siglo veintiuno Editores, Buenos Aires, 2016) p. 95; María Ángeles Barrere Unzueta, "Problemas del Derecho antidiscriminatorio: Subordinación versus discriminación y acción positiva versus igualdad de oportunidades", en Revista Vasca de Administración Pública (núm. 60, 2001) pp. 121-139, p. 16. 
reducción de la cárcel. Por ahora, la corrección de condiciones de exclusión previas a esta, la eliminación de estereotipos dirigidos al encarcelamiento de la pobreza y la adopción de medidas alternativas a la pena privativa de libertad, son del todo necesarias para la consecución de dicho objetivo. Por otra parte, la implementación de acciones afirmativas a favor de las personas reclusas que tornen eficaces los derechos no restringidos por la resolución que ordena la privación de libertad, tales como el derecho a la vida y la integridad física, a la salud, a la educación y al trabajo, contribuyen a corregir la desigualdad material que afecta al grupo y a compensar sus efectos.

Igualmente, y también en aplicación del principio de reintegración social de la persona condenada, cuyo propósito no es más que reducir al máximo posible los efectos desocializadores que genera la prisión ${ }^{37}$, se plantea la incorporación de la categoría de discriminación estructural en la labor interpretativa del juez de vigilancia penitenciaria. En efecto, reconociendo los sistemas de opresión que operan sobre este grupo antes, durante y después de la cárcel, el juez podrá incluir en su razonamiento jurídico la situación de desventaja que afecta al colectivo y con ello valorar el verdadero impacto de las normas que va a aplicar, pudiendo fallar conforme al contexto específico de la persona reclusa.

En definitiva, lo que se propone es que tanto las garantías tendientes a la descarcelación, la aplicación de determinadas acciones afirmativas y la interpretación contextualizada del juez de vigilancia penitenciaria a favor del respeto de la dignidad y los derechos de las personas reclusas, permiten dar un tratamiento diferenciado a los miembros de este grupo por la relevancia que tiene la prisión como fuente de discriminación. En efecto, tales medidas, como expresión de la dimensión diferenciadora de la igualdad, propenden a tratar como iguales a las personas reclusas en aquello que son iguales al resto de la sociedad. 38

\section{5.- BIBLIOGRAFÍA}

Añón Roig M.J., "Principio antidiscriminatorio y determinación de la desventaja", en Isonomía (núm. 39, 2013).

Alto Comisionado de la ONU para los Derechos Humanos, Recomendación Subcomité Contra la Tortura (2020).

Barrere Unzueta M.A., "Marta A. Fineman y la igualdad jurídica: ¿Vulnerabilidad vs. Subordiscriminación?", en Cuadernos Electrónicos de Filosofía del Derecho (núm. 34, 2016).

37 Santiago Mir Puig, Bases constitucionales del Derecho penal, cit., pp. 142 y 143. 38 En parte se sigue aquí lo que Laporta denomina la determinación de la relevancia de la diferencia, de modo que si esta no es relevante el tratamiento de los individuos debe ser igual, y viceversa, si es relevante, se justifica el trato diferenciado. Francisco Javier Laporta San Miguel, "El principio de igualdad: introducción a su análisis", en Sistema (núm. 67, Madrid, 1985) pp. 3-31. 
Barrere Unzueta M.A., "Problemas del Derecho antidiscriminatorio: Subordinación versus discriminación y acción positiva versus igualdad de oportunidades", en Revista Vasca de Administración Pública (núm. 60, 2001).

Cancio Meliá M., "De nuevo: ¿"Derecho penal" del enemigo", en Derecho penal del enemigo. El discurso penal de la exclusión, (vol. 1, Edisofer (España) Euro Editores (Buenos Aires) B de F (Uruguay), 2006).

Carranza E., "Situación penitenciaria en América Latina y el Caribe ¿Qué hacer?" en Anuario de Derechos Humanos (2012).

Centro de Derechos Humanos Facultad de Derecho Universidad Diego Portales, "Las personas privadas de libertad y el acceso a prestaciones de salud en las cárceles chilenas", en Informe Anual sobre Derechos Humanos en Chile (2019).

Codoceo F. y Ampuero F., "Apuntes iniciales sobre la instrumentalización política del "Sujeto peligroso"", en Fernando Codoceo, Fernanda Ampuero y Cecilia Pérez (Comps.), Criminalización de la pobreza. La construcción política del sujeto peligroso (Andros, Osorno, 2016).

Colegio Médico de Chile, Informe visita al centro de detención preventiva de Puente Alto en el contexto de pandemia coronavirus COVID-19 en el marco de los derechos humanos de las personas privadas de libertad (2020).

Comisión Interamericana de Derechos Humanos, Informe sobre los derechos humanos de las personas privadas de libertad en las Américas (núm. 455, 2011).

Corte Suprema de Chile, Situación recintos penitenciarios en pandemia COVID-19 (2020).

Eurosocial, Diagnóstico de la violencia institucional en las prisiones de América Latina: sistemas y buenas prácticas para su respuesta y atención (2018).

Ferrajoli L., "Criminología, Crímenes Globales y Derecho Penal. El debate epistemológico en la criminología contemporánea", en OSPDH (Trad.), Delitos de los Estados de los Mercados y daño social (Anthropos, Barcelona, 2014).

Ferrajoli L., "Jurisdicción y ejecución penal. La Cárcel: una contradicción institucional" en Iñaki Rivera Beiras (Trad.) Revista Crítica Penal y Poder (núm. 11, 2016).

Fiscalía Judicial Corte Suprema, Informe Principales problemas detectados en las visitas de cárceles realizadas el año 2017 por los fiscales judiciales (2018).

Fiscal Judicial de la Corte Suprema de Justicia, en La Segunda (2020).

Fiss O., "Grupos y cláusula de igual protección", en Roberto Gargarella (Comp.), Derecho y grupos desaventajados (Gedisa, Barcelona, 1999).

Instituto Nacional de Derechos Humanos, Estudio de las condiciones carcelarias en Chile. Diagnóstico del cumplimiento de los 
estándares internacionales de derechos humanos sobre el derecho a la integridad personal 2016-2017 (2018).

Jakobs G. y Cancio Meliá M., Derecho penal del enemigo (Thomson Civitas, Madrid, 2003).

Laporta San Miguel F.J., "El principio de igualdad: introducción a su análisis", en Sistema (núm. 67, Madrid, 1985).

Mir Puig S., Bases constitucionales del Derecho penal (Iustel, Madrid, 2011).

Ribotta S., "Reglas de Brasilia sobre acceso a la justicia de las personas en condición de vulnerabilidad. Vulnerabilidad, pobreza y acceso a la justicia", en Centro de Estudios Iberoamérica, Revista Electrónica Iberoamericana (vol. 6, núm. 2, 2012).

Rivera Beiras I., Descarcelación. Principios para una política pública de reducción de la cárcel (desde un garantismo radical) (2017).

Rivera Beiras I., "El nuevo Gran Encierro de la Modernidad Tardía" en Iñaki Rivera Beiras (Coord.) Pandemia. Derechos Humanos, Sistema Penal y Control Social (en tiempos de coronavirus) (Tirant Humanidades, 2020).

Saba R., Más allá de la igualdad formal ante la ley ¿Qué les debe el Estado a los grupos desaventajados? (Siglo veintiuno Editores, Buenos Aires, 2016).

Subcomité para la Prevención de la Tortura y Otros Tratos o Penas Crueles, Visita a Chile: recomendaciones y observaciones dirigidas al Estado parte (4-13 de abril de 2016) (2016).

Torbisco Casals N., "La institucionalización de la diferencia: algunas notas sobre desigualdad estructural y democracia", en LoS límites de la democracia (Editores del Puerto, Buenos Aires, 2005).

Young I.M., La justicia y la política de la diferencia (Cátedra, Madrid, 2000).

Zaffaroni E., El enemigo en el Derecho penal (Ediar, Buenos Aires, 2006).

Zaffaroni E., Estructura básica del Derecho penal, Material de la cátedra de Teoría del Delito del Prof. Matías Bailone en la Maestría en Derecho Penal de la Universidad Andina Simón Bolívar (Ecuador). 